\title{
Consent to Treatment by the Mentally Ill and Mentally Handicapped \\ An Anomaly in the Mental Health Act 1983
}

BRIDGrT C. Dimond, Barrister-at-Law, Department of Management and Legal Studies, Polytechnic of Wales, Pontypridd, Mid Glamorgan

I would like to bring to light an apparent oversight in the new statutory rules relating to consent to treatment by the mentally ill and mentally handicapped. This will have very serious consequences for the management of patients who are on short-term detention orders. The provisions relating to consent to treatment set out in Part IV of the Mental Health Act 1983 are the first attempt to cover by statutory controls the doctor's clinical freedom to prescribe treatment for his compulsorily detained patient. In addition, certain of the new provisions (which take effect from 30 September 1983) apply to the voluntary patients as well.

The scheme for consent to treatment is as follows:

Section 57, which covers surgery, involving the destruction of brain tissue or its functioning, plus other treatments to be specified by the Secretary of State, requires the following conditions: (a) the consent of the patient; (b) the certification of this consent (as being given by a patient capable of understanding the nature, purpose and likely effects of the treatment) by an independent doctor and two approved nonmedical persons; (c) a certification by the same independent medical practitioner that the treatment should be given; (d) consultation by this doctor with two persons professionally concerned with the patient's medical treatmentone of whom must be a nurse, and the other neither nurse nor a medical practitioner.

Section 58 covers ECT and other forms of treatment to be specified by the Secretary of State and other treatments (not covered by Section 57) where three months have elapsed since treatment was first given to a detained patient. Requirements for this section are that: (a) the patient must either consent, and either the patient's doctor or an independent medical practitioner certify the patient's capability and giving of consent; or (b) the patient either is incapable or refuses to consent and an independent doctor certifies this to be the case, but that the treatment should be given; and (c) before giving a certificate under (b), the independent doctor consults with two other persons professionally concerned in the patient's medical treatment, one of whom is a nurse and the other neither nurse nor medical practitioner.

Section 63: Treatment not falling within Section 57 or Section 58 does not require the consent of the patient, provided the treatment is given by or under the direction of the responsible medical officer.

Section 62: Urgent treatments-certain treatment can be given where it is immediately necessary. The type of treatment permitted relates directly to the seriousness of the patient's condition.

Applications of these Sections

Part IV (Section 56) of the 1983 Act begins with its application to any patient liable to be detained under the 1983 Act, except those under Sections 4, 5(2) and 5(4), $37(4), 135$ or 136 and $42(2)$. In other words, patients detained under Sections 25, 26, 60 and 65, 72 (of the 1959 Act) are all covered by the new laws on consent to treatment, i.e. Sections 57, 58, 63 and 62.

In addition, however, Section 56(2) applies Sections 57 and 62 to any patient who is not liable to be detained under the 1983 Act-i.e. all voluntary patients; the provisions on brain surgery apply to them, as do the emergency treatment provisions.

What, however, about those detained patients who are excluded from the provision of Part IV under Section 56do the emergency treatments not apply to them? The answer would appear to be no. They are excluded under Section 56, but not covered by Section 56(2) and remain outside Part IV. From strict interpretation of these Sections, it would appear that if a voluntary patient suddenly becomes very disturbed and aggressive, it would be possible to give the patient, without his consent, treatment which was neither irreversible nor hazardous, which was immediately necessary, and which represented the minimum interference necessary to prevent the patient behaving violently or being a danger to himself or others. Yet as soon as the holding power of the nurse is commenced under Section 5(4) or the medical practitioner in charge of the patient (or his nominated substitute) holds the patient under Section 5(2), the statutory provisions relating to emergency treatment do not apply. Similarly, if a patient is detained under Sections 4 (29 in the old 1959 Act), 135 and 136 of the 1983 Act and those other Sections listed in Section 56, it will not be possible to give the patient emergency treatment under the Act. Presumably, emergency treatment under the doctor's common law duty of care for the patient would still exist and could be relied on. Yet the whole purpose of Part IV of the Act was to replace the confused situation relating to consent to treatment by clear statutory guidelines.

Such an anomaly could surely not have been intended by the legislature, and many practical problems may arise from it. The inability to give emergency treatment to this group of people may well mean that in practice, instead of detaining a patient under Section 5(2), a voluntary patient may be treated in an emergency, which may well have the effect of detaining him de facto if not de jure. 